\title{
Signatures of Selection on Growth, Shape, Parr Marks, and SNPs Among Seven Canadian Atlantic Salmon (Salmo Salar) Populations
}

\author{
Mark Culling ${ }^{1, \wedge}$, Heather Freamo ${ }^{1}$, Kristen Patterson ${ }^{1}$, Paul R. Berg ${ }^{2, \wedge}$, Sigbjørn Lien², \\ Elizabeth G. Boulding ${ }^{1, *}$
}

\author{
${ }^{1}$ Department of Integrative Biology, University of Guelph, 50 Stone Road E., Guelph, Ontario, N1G 2W1, Canada \\ ${ }^{2}$ Department of Animal and Aquacultural Sciences and Centre for Integrative Genetics (CIGENE), Norwegian Univer- \\ sity of Life Sciences, PO Box 5003, N-1432 Ås, Norway
}

\begin{abstract}
Successful re-introduction of captively-bred Atlantic salmon (Salmo salar) populations to their historical natal river systems may be difficult until patterns of local genetic adaptation by the parr stage are better understood. Divergence in parr size, shape, pigmentation, and SNP allele frequencies was compared for five endangered salmon populations from the Bay of Fundy. Differences among populations in body weight at age, morphometrics, and parr mark pigmentation persisted in a common hatchery environment. Twelve out of 207 mapped SNPs were identified as outliers under diversifying selection by Arlequin 3.5's hierarchical island neutrality test and one of these was also identified by Bayescan $2 . F_{\mathrm{ST}}$, the molecular divergence for the 12 outlier SNPs was comparable to $P_{\mathrm{ST}}$, the phenotypic divergence, but $F_{\mathrm{ST}}$ for the remaining 195 "neutral" SNPs was significantly smaller. One SNP in a trypsin inhibitor showed a strong phylogenetic signal between inner and outer Bay of Fundy that was correlated with the slower growth rates, deeper bodies, and longer pectoral fins of parr from inner Bay rivers. Mantel tests for seven populations showed a significant correlation between the matrix of pairwise $F_{\mathrm{ST}}$ values for the non-outlier "neutral" SNPs only for the matrix of body weights at age. Thus with the exception of body weight, pairwise distances among these complex traits were not correlated with molecular genetic distance estimated from neutral SNP markers. However, the matrix of parr mark numbers was inversely correlated with the matrix of parr mark contrast values and may therefore represent convergent local genetic adaptation.
\end{abstract}

Keywords: Geometric morphometrics, local adaptation, molecular markers, New Brunswick, outlier locus.

\section{INTRODUCTION}

Climate change and other anthropogenic effects are causing Canadian Atlantic salmon populations to become extinct at an unprecedented rate [1] making it critical to document the extent of local genetic adaptation. Reintroduction of captively-bred populations to their historical natal rivers has been successfully accomplished in Norway [2] and is planned in Canada as part of the Live Gene Banking program $[3 ; 4]$. However, choosing the best source population for a re-introduction, after the original population has gone extinct, will be easier once patterns of local genetic adaptation to particular streams are better understood. The preservation of hundreds of locally-adapted populations has been shown to buffer salmon populations against environmental stochasticity thus reducing the need for fisheries closures [5].

\footnotetext{
*Address correspondence to this author at the Department of Integrative Biology, University of Guelph, 50 Stone Road E., Guelph, Ontario, N1G 2W1, Canada; Tel: 1-519-824-4120; Ext: 54961; Fax: 1-519-767-1656; E-mail: boulding@uoguelph.ca

$\wedge$ Present Addresses: Biological Sciences, Hull University, Hull, HU6 7RX, United Kingdom; Centre for Ecological and Evolutionary Synthesis (CEES), Department of Biology, University of Oslo, P.O. Box 1066 - Blindern, N-0316 Oslo, Norway
}

Salmonid fishes have long been recognized as having phenotypes that match their environments [6-8]. Differences in head and body shape in Atlantic salmon are correlated with the stream gradient $[9,10]$. Parr from northern Norway have smaller heads, eyes, jawbones, and pectoral fins than parr from or southern Norway [11]. Recent reviews have concluded that this match between complex traits, such as morphology, and environment is partially genetic and partially adaptive phenotypic plasticity $[12,13]$. Genetic adaptation of parr to particular freshwater environments has been shown for early growth rate $[14,15]$, fin size and shape [16], body shape, and the number and the contrast of the parr marks [12]. Complex traits have been shown to rapidly evolve in salmon populations $[13,17]$ likely because salmon both exhibit reproductive fidelity to their natal freshwater environments [7, 2] and have high fecundities [18]. The resulting low migration, and ability to tolerate high selection intensities, can result in rapid evolution of heritable parr traits to towards the local optima for a particular stream environment [19]. However, rearing experiments have shown that parr body shape [20] and caudal fin shape [21] are phenotypically plastic making interpretation of patterns observed in nature difficult. 
Molecular signatures of local adaptation by salmonid fishes have recently been detected using multiple-markerbased 'neutrality' tests to identify genes and genomic regions potentially affected by positive (or diversifying) natural selection [22-25]. Single nucleotide polymorphisms (SNPs) in or near protein coding genes have been used as markers to identify locally adapted regions of the genome under positive selection [reviewed 26]. The benefits of using SNPs over previous molecular markers include semiautomatic scoring, low scoring error rates, the availability of high densities of easily annotated markers, and the relative ease of calibration among laboratories [27]. The 320 SNPs used here were discovered by aligning Atlantic salmon sequences for protein coding genes from Expressed Sequence Tags (EST) databases [28]. Freamo et al. [29] found that a subset of these SNP loci under positive selection performed better than a larger subset of "nearly neutral" SNP loci in assigning individual salmon to either the Inner or Outer Bay of Fundy region. mtDNA data suggest that Atlantic salmon populations from the inner Bay of Fundy (iBoF) and outer Bay of Fundy (oBoF) represent different phylogenetic lineages [30]. Adult $i B o F$ salmon differ from oBoF salmon in a number of important life history characteristics such as local adult migration rather than adult migration to western Greenland [1] but show only small differences in allele frequencies at neutral microsatellite loci [reviewed by 31].

In this paper we document differences in growth rate, body shape, and parr mark patterns among five endangered
Atlantic salmon populations reared in a common hatchery environment until the parr stage and then genotyped for 320 SNPs. We used neutral and non-neutral subsets of the 207 polymorphic SNP markers to estimate $F_{\mathrm{ST}}$ statistics between all pairs of populations. Our aim was to compare the amount of molecular divergence among populations at neutral and at non-neutral SNP loci with the magnitude of phenotypic differences in growth rate, body shape, and parr mark pigmentation.

\section{MATERIALS AND METHODOLOGY}

\section{Study Populations}

Approximately 30 to 32 parr from each of seven populations from the Bay of Fundy were sampled at the Mactaquac Fish Hatchery on 30 June 2006 (Table 1). The five focal populations used in our study are all endangered [1] and include two iBoF populations: the Upper Salmon River (USR); and the Big Salmon River (BSR) and three oBoF: the Hammond (HAM) River; the Serpentine (SER) River; and the Tobique (TOB) River. The relative geographic location of these rivers is shown in Fig. (1). We also sampled parr from the non-anadromous Chamcook Lake (CHA) and from a hybrid population derived from the extirpated St. Croix River population (STC) and some TOB males. The sampled fish that had been reared under the same environmental conditions at the Accelerated Rearing Facility (ARF) beside the Mactaquac dam on the Saint John River from November

Table 1. The Average Weight of a Parr from Each Population, Just before the Fish were Moved from a Common Environment in the Early Rearing Facility to the Mactaquac Fish Hatchery Where they were Held for Two Weeks at the Water Temperature Indicated

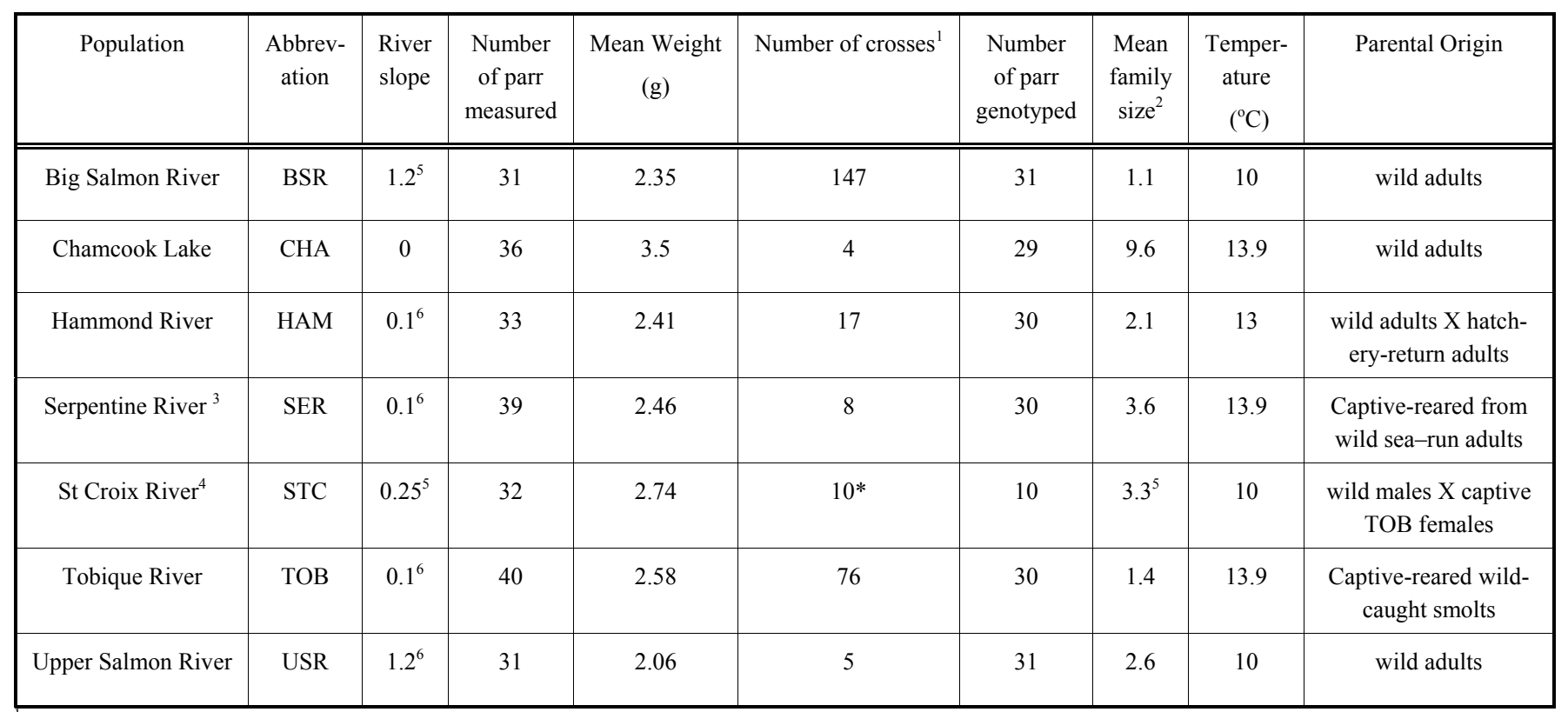

${ }^{\mathrm{I}}$ Families are full-sib families from single pair matings for all populations except STC.

${ }^{2}$ Mean full-sib family size in sample that was SNP genotyped using Colony 2.0. The estimates for the five focal populations: BSR, HAM, SER, TOB and USR are from Freamo et al. [29]. Methods for estimates for CHA and STC are presented in Supplementary Appendix C.

${ }^{3}$ SER parr were the progeny of wild sea-run adults captured in the fishway at the Mactaquac dam. Their size, scale growth pattern, and their first arrival at the Mactaquac dam are life history traits characteristic of the historical SER stock (Trevor Goff, pers. comm. to EGB).

${ }^{4}$ Only a single STC female was available to cross with four STC males to produce 4 half-sib 'pure' STC parr families. Therefore, the 4 STC sea-run males were also crossed with six captive raised TOB females to create 10 additional families.

${ }^{5}$ From [72].

${ }^{6}$ From [82]. Mean slope value (metres per kilometre) for Saint John River used for HAM, TOB, SER, Point Wolf River value used for USR. 
2005 to 12 June 2006 as part of the Live Gene Banking program [3]. On 12 June 2006, samples of parr from each population were weighed and then moved over the river to the Mactaquac Hatchery in New Brunswick, Canada where, during the final two weeks of their existence (week beginning 12 June to 30 June 2006), they experienced some differences in water temperatures (Table 1). The inner Bay of Fundy populations have to be reared in well water rather than river water from the Saint John River to avoid disease transfer (T. Goff, pers. comm. to EGB.). All the above progeny resulted from artificial hatchery spawning of the chosen wild-caught adults except for CHA parr, which resulted from crossing wild landlocked adults that were spawned at the lakeside (Table 1).

\section{Data Acquisition}

After capture with a dip net, each fish was anaesthetized (Aquacalm, Synddel Laboratories Ltd, British Columbia), weighed, and then positioned laterally, left side up, on a measured grid page where the length and a digital image of each individual was recorded (Olympus Camedia 3040ZOOM camera with 3.2 Mega Pixels resolution) using standard lamps for all photographs. Finally, a caudal fin clip sample was taken for molecular analyses. All photographs were taken from the same angle and a standard ruler included in each photograph for scaling.

\section{Parr Mark Number and Contrast Data}

We used the fish images in the digital photographs to count the number of parr marks on the side of each fish. To quantify the contrast of the parr mark against the lighter skin we used the eyedropper tool in Adobe Photoshop 7.0. For each image, a $5 \times 5$ pixel brightness measure was taken from the centre of each parr mark using the eyedropper tool (Fig. 2). Moving anteriorly from the measured parr mark, a second skin-background ( $5 \times 5$ pixel brightness) value was recorded from the central point between parr marks along the lateral line. The two types of measured values were recorded as parr mark and skin brightness values for each of the visible parr marks along the fish's body (Fig. 2). Contrast values for each parr mark were then calculated as the ratio of the skin colour brightness to the respective parr mark brightness value as suggested by Marit Gjerstad of PhotoFisk of Âs, Norway so as to be more independent of ambient light (email to E.G.B). The skin is always brighter than the parr mark so the ratio is a positive number that becomes larger when the parr mark is darker. Brightness values were recorded for all parr marks

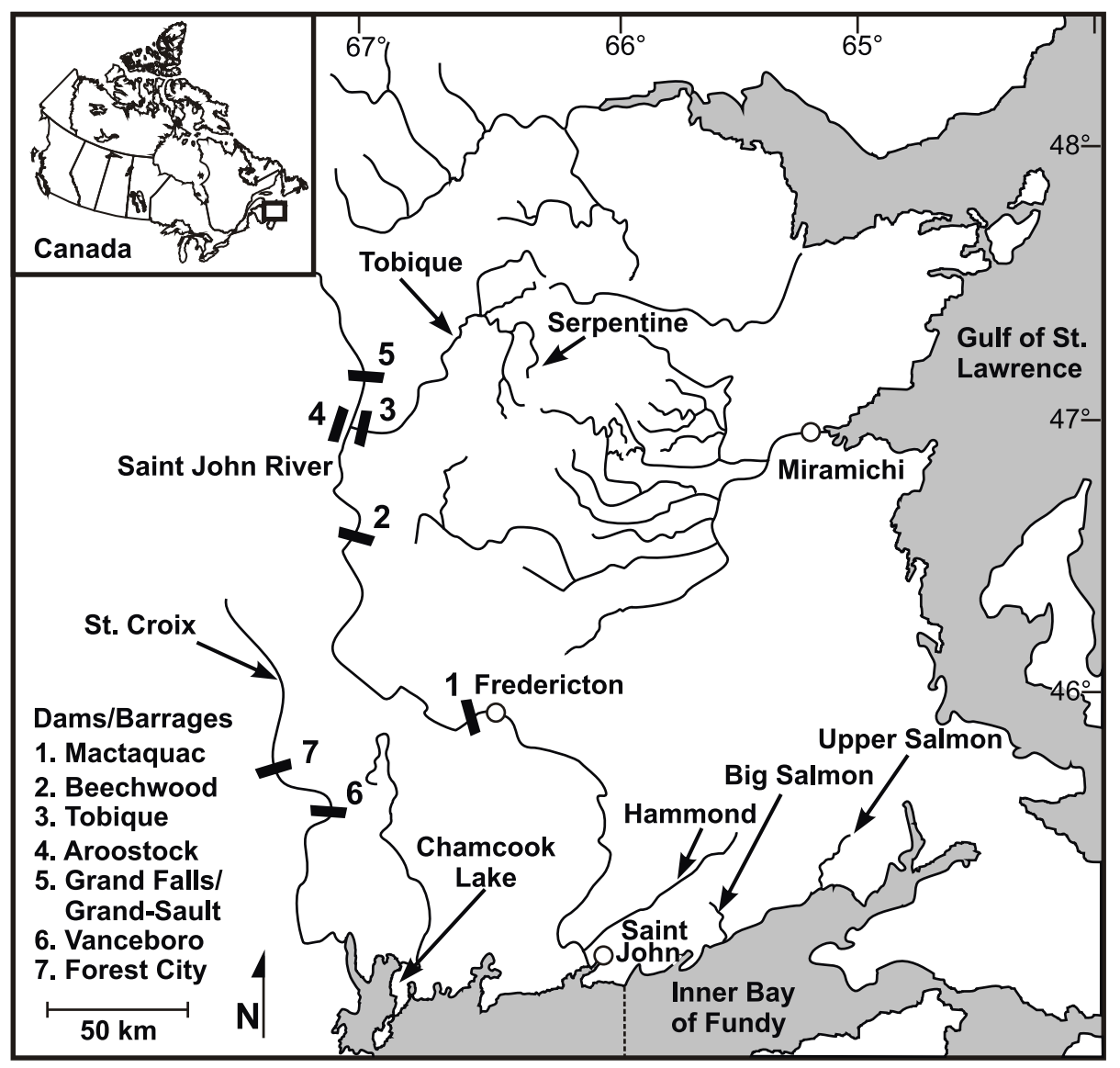

Fig. (1). Map of New Brunswick, Canada showing the location of seven Atlantic salmon populations sampled. The Big Salmon (BSR) and Upper Salmon (USR) rivers are part of the Inner Bay of Fundy region. The Hammond (HAM), Tobique (TOB) rivers are tributaries of the St. John River system and the Serpentine (SER) is a headwater tributary of the Tobique River and, along with St. Croix River (STC), are part of the Outer Bay of Fundy region. Chamcook Lake (CHA) is the only landlocked lake population originally transplanted from landlocked Skiff Lake (Brian Glebe, pers. comm.). 
along the body and the contrast values were averaged over all parr marks for a particular fish and then used to find the mean colour contrast value.

We estimated how repeatable our parr mark measurements were using a dataset from 50 full-sib Atlantic salmon parr that had been pit-tagged and then photographed again within a four month period for another study [32]. We found that the correlation between the August and November measurements was higher for parr marks number $(\mathrm{r}=0.892$, $\mathrm{p}<0.001)$ than for parr mark contrast $(r=0.448, p=0.001)$ likely because the mean contrast had decreased significantly over the four month period (paired t-test, $\mathrm{p}=0.014$ ).

We tested for a phenotypic correlation between the average number of parr marks and the mean contrast values for each population. We also ran univariate ANOVAs with SPSS v.15 then did Tukey post hoc tests SYSTAT W5.0 to determine whether the two dependent variables: parr mark number and parr mark contrast were significantly different among the different populations.

\section{Morphological Data Acquisition}

Landmark based geometric morphometrics were used to acquire shape data. Fifteen landmarks (Fig. 2) were digitized on each image using TPSDIG2 2.05 [33]. The power of aligned landmark and geometric morphometric analyses is inversely proportional to the number of landmarks for a given number of specimens [34]; therefore, 15 consistently repeatable landmarks were chosen to capture the overall body shape. The repeatability of our landmark co-ordinates was assessed by having different people digitize the same photograph and found to be very high.

The program TPSRELW 1.44 [35] uses generalized orthogonal least squares Procrustes procedures [36], to align, scale and rotate the landmark configurations to superimpose the digitized landmarks. The shape variables used in the statistical analyses were aligned landmarks (for methods and results from the geometric morphometric analyses, including visualization of shape differences using deformation grids, see Appendices A \& B in Supplementary Material) acquired from the superimposed specimens using TPSRELW 1.44 [35]. The aligned TPS co-ordinates were used to estimate the centroid size for each fish using TPSREGR 1.31 [37]. Cen- troid size is deemed to be a reliable size measure, theoretically [38], and empirically, based on earlier fish studies, which have found strong correlations between centroid size and standard length [39].

Procrustes distances between all pairs of populations were computed using the TwoGroup7 module of IMP 7.1 $[40,41]$. This pairwise distance measured how far a composite size-standardized "reference form from one population was from the reference form for a second population in common geometric shape space. To determine whether different populations were significantly different in shape, Pvalues were estimated using a resampling F-test using 900 bootstraps.

All 15 aligned landmarks in XY co-ordinate space were used as independent variables in a discriminant function analysis (DFA) of five Atlantic salmon populations using SPSS. This resulted in four canonical variates that summarized shape variation. The main manuscript contains analyses of only five Atlantic salmon populations but our initial analyses were carried out with all seven populations and are presented in separate figures and tables in the Supplementary Material. CHA was removed from the main analysis because it was so morphologically differentiated that it masked subtle differences between the five focal populations that are endangered. STC was removed from the main analysis because $60 \%$ of the families were comprised of hybrid progeny derived from crosses between STC males and TOB females which made interpretation of the results more challenging.

\section{Molecular Data Acquisition}

We genotyped all seven Atlantic salmon populations for 320 mapped SNP loci developed from EST libraries for Atlantic salmon using the MassARRAY ${ }^{\mathrm{TM}}$ system from Sequenom (San Diego, USA) [42]. The CIGENE 6K SNp Chip for the North American subspecies of Atlantic salmon, that we used, does not suffer from the problem of ascertainment bias [43]. All populations except for CHA and STC were the same individuals analyzed by Freamo et al. [29]; however their SNP analysis also included three additional populations: (PWF, STW, and CAN) for which no morphological data was available. Each individual fish was genotyped for at

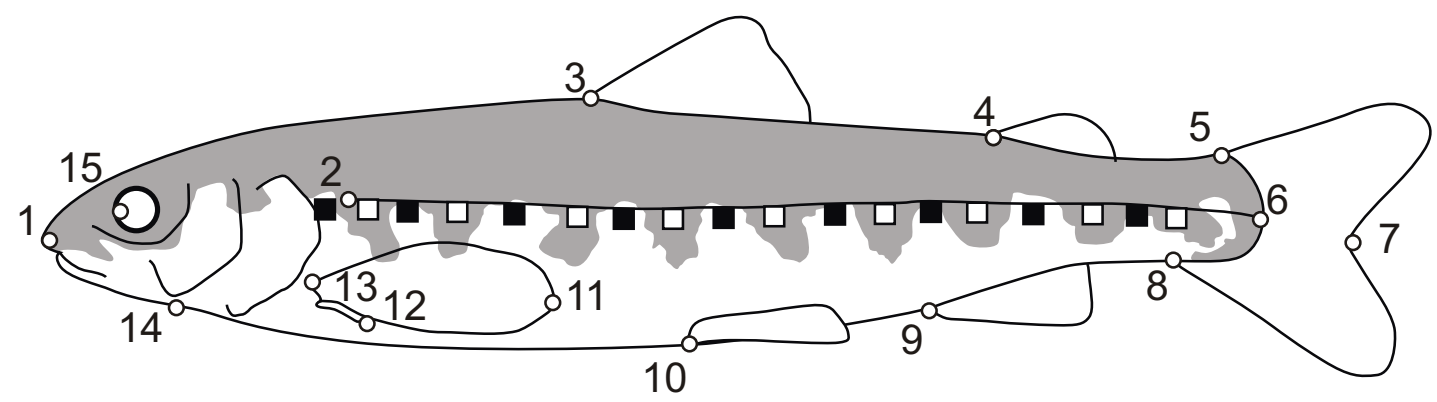

Fig. (2). Positions of pixel sampling on light (black squares) and dark (white squares) areas of skin with Adobe Photoshop v 7.0 for calculations of parr mark number and contrast. Placement of 15 landmarks (white circles) with TPSDIG 1.37 [33] for geometric morphometric analysis: (1) tip of snout, (2) anterior beginning of lateral line, (3) anterior insertion of dorsal fin, (4) anterior insertion of adipose fin, (5) dorsal insertion of caudal fin, (6) most posterior mid-point of caudal peduncle, (7) fork point in caudal fin, (8) ventral insertion of caudal fin, (9) anterior insertion of anal fin, (10) anterior insertion of pelvic fin, (11) most posterior point of pectoral fin, (12) ventral and more dorsal (13) insertions of pectoral fin, (14) point where operculum joins the outline of body (ventral), and (15) most anterior point of pupil. 
least two EST-SNPs per chromosome using 15 separate PCR reactions with multiplexing levels that were between 20 and 34 loci per reaction [see 29]. To ensure full 96 well plates, most but not all of the individuals that were measured were genotyped.

\section{Molecular Population Genetic Differentiation}

Pair-wise population $F_{\mathrm{ST}}$ values [44] were calculated for five Atlantic salmon populations using the 10,000 locus version (Jérôme Goudet, pers. com.) of the program FSTAT 2.9.3.2 [45] using various subsets of SNP loci. $P$-values were obtained after 10,000 replicates with an adjusted $\alpha$ of 0.0050 for multiple comparisons. We also used FSTAT to examine whether any the allele frequencies at any SNP locus deviated significantly from Hardy-Weinberg Equilibrium (HWE).

\section{Methods for Detection of $\boldsymbol{F}_{\mathrm{ST}}$ Outlier loci}

Loci with higher $F_{\text {ST }}$ values relative to that expected under neutrality can be the outcome of directional selection towards different optima in different environments [46]. We carried out five replicate runs for each of the two methods using the program defaults unless otherwise specified.

Method 1.- We used "Bayescan 2.0" [47] which uses a hierarchical-Bayesian model that is similar to the original $F_{\mathrm{ST}}$-outlier test, FDIST (48], but does not assume the same $F_{\mathrm{ST}}$ value for each sub-population [49]. The program calculates the Posterior Odds (PO), from the posterior probability of the models with and without selection on a locus [50], by using the proportion of loci with a strong increase in $F_{\mathrm{ST}}$ relative to other loci among the Markov Chain Monte Carlo outputs of its simulations [49]. The new default 10:1 prior odds for Bayescan 2.0 assumes that the neutral model is 10 times more likely than the model with selection instead of the 1:1 default that was used in version 1.0 [50] and requires either using Posterior Odds (PO) level or a False Discovery rate (FDR) level to decide whether a locus is an outlier or not [47] and based on our experience, we chose the former and set $\mathrm{PO}=1.0$ which corresponds to "Strong" on Jeffrey's scale of evidence [50]. The weakness of this program is that it does not account for population structure [51, 52]. With our fine geographic scale dataset it is more conservative than outlier programs based on Fst and heterozygosity so may suffer from Type II error [48, 49] although a recent analysis of simulated data found lower Type II error rates [53].

Method 2.- Arlequin 3.5 is designed to give fewer false positive $F_{\mathrm{ST}}$ outlier loci by accounting for historical metapopulation structure with a hierarchical island model [54, 55]. We further reduced the number of false positive $F_{\mathrm{ST}}$ outlier loci by only including loci in the top one percentile. The program uses a similar algorithm to the $n$-island model of FDIST [48] but assumes: 1) that the average migration rate among populations on different islands is lower than that between demes on the same island; 2) a specific SNP model for DNA sequence data; and 3) the heterozygosity between populations can be inferred using the heterozygosity within a population [56]. We structured our analysis so that $\mathrm{iBoF}$ populations were grouped together and $\mathrm{oBoF}$ populations, were grouped together as this was supported by the above STRUCTURE analysis of our own dataset (see Appendix D in Supplementary Data) and by an AMOVA analysis of a partially overlapping SNP dataset with four inner and four outer populations [29].

The map position of all outlier loci found was then compared to that of QTL loci found using backcrosses between North American and European Atlantic salmon [32]. Mapping of an outlier locus to a chromosome arm that contained a QTL locus for an adaptive trait is the first step towards supporting their status as genuine outliers as opposed to analytical artefacts $[23,57]$. However, markers that are informative in QTL-mapping may not be detected in $F_{\mathrm{ST}}$-based outlier analysis. The low number of crossovers that occur during single generation crosses made for QTL mapping may cause linkage disequilibrium (LD) to extend over large distances especially if the population was founded from a low number of individuals [e.g. 58 ]. In contrast LD would be expected to be much less in large, outbred, wild populations, where hundreds of generations of recombination/mutation can result in $F_{\mathrm{ST}}$-outlier markers being detected only when there is close physical linkage [e.g. 58].

\section{Comparison of Molecular genetic and Morphological Divergence}

The amount of divergence in genes coding for quantitative traits is usually estimated by $Q_{\mathrm{ST}}$. When $Q_{\mathrm{ST}}$ for a trait is larger than $F_{\mathrm{ST}}$ then genetic drift is not sufficient to explain its divergence; and therefore, selection must also be responsible [e.g. 59]. However, estimation of $Q_{\mathrm{ST}}$ requires estimating heritability within populations which requires rearing of offspring of a large number of known parents in a common environment. Here we used $P_{\mathrm{ST}}$, which is analogous to $Q_{\mathrm{ST}}$, but can be inflated by environmental and non-additive genetic effects shared by individuals from the same population [60]. $P_{\mathrm{ST}}$ is frequently being used as a surrogate for $Q_{\mathrm{ST}}[61$, 62 ], perhaps because it can be estimated from wild-collected individuals.

$P_{\text {ST }}$ was estimated (equation 1 in [63]) as:

$\mathrm{P}_{\mathrm{ST}}=\sigma_{\mathrm{GB}}^{2} /\left(\sigma_{\mathrm{GB}}{ }^{2}+2\left(\mathrm{~h}^{2}{\sigma_{\mathrm{Gw}}}^{2}\right)\right)$

where $\sigma_{\mathrm{GB}}{ }^{2}$ is the phenotypic variance between populations, $\sigma_{\mathrm{GW}}{ }^{2}$ is the phenotypic variance within populations, and $\mathrm{h}^{2}$ is the narrow sense heritability which here was unknown. Consequently $h^{2}$ was conservatively set to the average value for non-life history traits of 0.5 [64]. The actual heritabilities are likely smaller than 0.5 , for example body weight in the Saint John River aquacultural strain has a heritability of 0.1-0.2 [65], but smaller heritability values in the denominator would make Pst even larger. Confidence intervals (95\%) were calculated by bootstrapping the raw data in SAS to make 100 new datasets. The variables included weight, centroid size, Procrustes distance to a single reference form based on all landmarks, and the two significant aligned morphometric landmarks $1 \mathrm{X}$ and $3 \mathrm{Y}$ that were not significantly correlated with centroid size. The mean and standard deviation of $P_{\mathrm{ST}}$ was estimated from the distribution of $P_{\mathrm{ST}}$ values from the 100 bootstrap datasets.

Mantel tests of matrices containing pairwise phenotypic or genetic distances for all seven wild Atlantic salmon populations: BSR, CHA, HAM, SER, STC, TOB, USR were 
computed using MANTEL for Windows1 version 1.19 [66]. MANTEL permutates matrices with 100,000 randomizations to calculate the one-tailed probability that $\mathrm{Z}$ is larger than $\mathrm{Z}$. The distance measure used in the matrices for body weight, parrmark number and parrmark contrast was the absolute value of the mean difference with no transformation. The distance measure for body shape was the pairwise Procrustes distance among the size-standardized averaged $\mathrm{x}$ and $\mathrm{y}$ coordinates for each population [40] calculated using IMP71 [67]. The matrices of pairwise $F_{\mathrm{ST}}$ values were compared with the phenotypic matrices. The first $F_{\mathrm{ST}}$ matrix used all 195 neutral SNPs below the 5\% upper quantile and the second $F_{\mathrm{ST}}$ matrix used all outlier SNPs above the 5\% upper quantile as calculated by the $F_{\mathrm{ST}}$ outlier module in Arlequin 3.5.

\section{RESULTS}

\section{Parr Mark Number and Contrast}

There were significant differences in parr mark number among five populations of juvenile Atlantic salmon from different rivers (ANOVA, $F=23.01, d f=4, p<0.001$ ). HAM and SER had significantly fewer parr marks on average than the remaining populations (Fig. 3). The highest mean number of parr marks was found in the TOB population (mean=7.8) and the lowest number was found in the SER population (mean=5.8). There were significant differences in parr mark contrast among five populations (ANOVA, $F=$ $51.12, d f=4, p<0.001)$. BSR and USR (iBoF) differed significantly in their mean contrast values (Fig. 3), with USR having the highest mean contrast value (2.08) and, therefore, the most distinct parr marks of all the populations (Fig. 3).
The HAM and SER (oBoF) had significantly lower mean contrast values (1.51 and 1.32); and therefore, the least distinctive parr marks of all the other populations, with the SER population having significantly lower mean contrast values than all the other populations except for the HAM (Fig. 3). Populations with a higher mean number of parr marks also had higher mean average contrast value (Fig. 3). Additional statistical analysis with population and parr mark number as the two factors showed that there were significant differences in average contrast values even when the particular parr marks (the first or the second mark) were compared among populations (E.G. Boulding, unpublished data).

\section{Geometric Morphometrics Comparisons}

The Procrustes distances computed with TwoGroup7 module of IMP 7.1 were significantly different between all pairs of populations except for two. BSR was not significantly different in shape from USR (Table 2). Also BSR was not significantly different from TOB after correction for multiple testing (Table 2).

The discriminant analysis using the aligned landmarks found significant differences among the five populations of juvenile Atlantic salmon in their overall body shape $(\Lambda=$ $0.046, \chi^{2}(d f=104, N=174)=486.64, p<0.001$; Supplementary Appendix A: Table 1S). Furthermore, these individuals could be accurately classified into the five populations $\left(\Lambda=0.208, \chi^{2}(d f=75, N=174)=247.38, p<0.001\right)$ based upon their aligned coordinates, after removing the effects associated with the first discriminant function (Supplementary Appendix A: Table 5S). Four discriminant func-

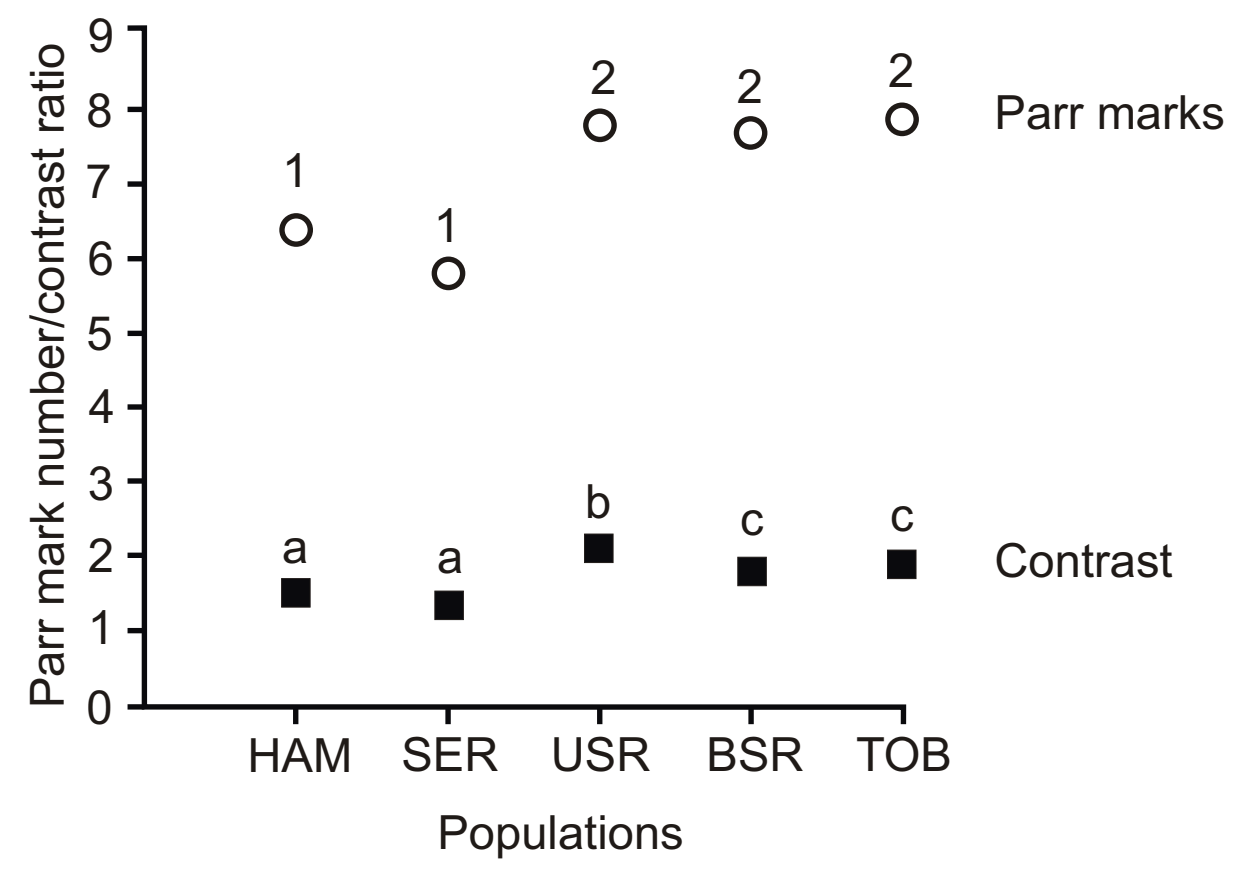

Fig. (3). Average contrast values (filled square) and number of parr marks (open circles) for five Atlantic salmon populations. Univariate ANOVA for Parr marks $P<0.0001$. Significant pairwise differences (Tukey post hoc test $\alpha=0.05$ ) for average number of parr marks are represented with different numbers for each homogeneous subset. Univariate ANOVA for average contrast $\mathrm{P}<0.0001$. Significant differences (Tukey post hoc test $\alpha=0.05$ ) for average contrast between each parr mark and its corresponding anterior skin sample are represented by different letters for each homogeneous subset. 
Table 2. Procrustes Distances From the CoordGen7a Module of IMP 7.0 [67]. Below Diagonal: Pairwise Procrustes Distances in Common Geometric Shape Space After Removal of Centroid Size Using the Residuals From a LN Regression With Standard7 Module. Above Diagonal: P-values From a Resampling F-test From the Two Group7 Module Using 900 Bootstraps

\begin{tabular}{|c|c|c|c|c|c|}
\hline POP & BSR & HAM & SER & TOB & 0.0578 \\
\hline \hline BSR & - & $0.0011^{*}$ & $0.0011^{*}$ & $0.0011^{*}$ & 0.2367 \\
\hline HAM & 0.0177 & - & $0.0011^{*}$ & $0.0011^{*}$ & $0.0011^{*}$ \\
\hline SER & 0.0179 & 0.0083 & - & - & 0.0200 \\
\hline TOB & 0.0329 & 0.0376 & 0.0338 & 0.0369 & - \\
\hline USR & 0.0150 & 0.0140 & 0.0148 & & \\
\hline
\end{tabular}

* Significant at $\alpha=0.05$ after Bonferroni correction for multiple tests $\left(\alpha^{\prime}=0.0055\right)$.

tions were interpreted (Table 1S) because of the significance of both multivariate and univariate tests. Differences among the five population groups accounted for $66.6 \%$ of the variability on the first discriminant function and fell to $13.9 \%$ for the fourth and final discriminant function (Table 5S). Correct group membership was determined from $80.6 \%$ to $54.8 \%$ of the time for all five populations (Supplementary Appendix A: Table 6S). Overall, 69\% cross-validated grouped cases were correctly classified.

Shape variation from the DFA of the aligned landmarks for the five populations showed that morphological variation was in both the anterior and posterior regions (Fig. 4). Canonical variate 1 (cv1), accounting for $66.6 \%$ of the total variation, expressed a decreasing body depth, and shortening and narrowing of the pectoral fin (Fig. 4; Table 5S). Scores on Cv1 were significantly different for all pair-wise population comparisons except for BSR and USR as well as HAM and SER. An increase in the length of the posterior of the fish, a shortening and narrowing of the pectoral fin, an increase in body depth, and lowering of the snout are represented by canonical variate 2 , which accounted for $48.4 \%$ of variation across the body form (Fig. 4; Table 5S). The scores on cv2 were significant in all $(80 \%)$ of the pair-wise popula-

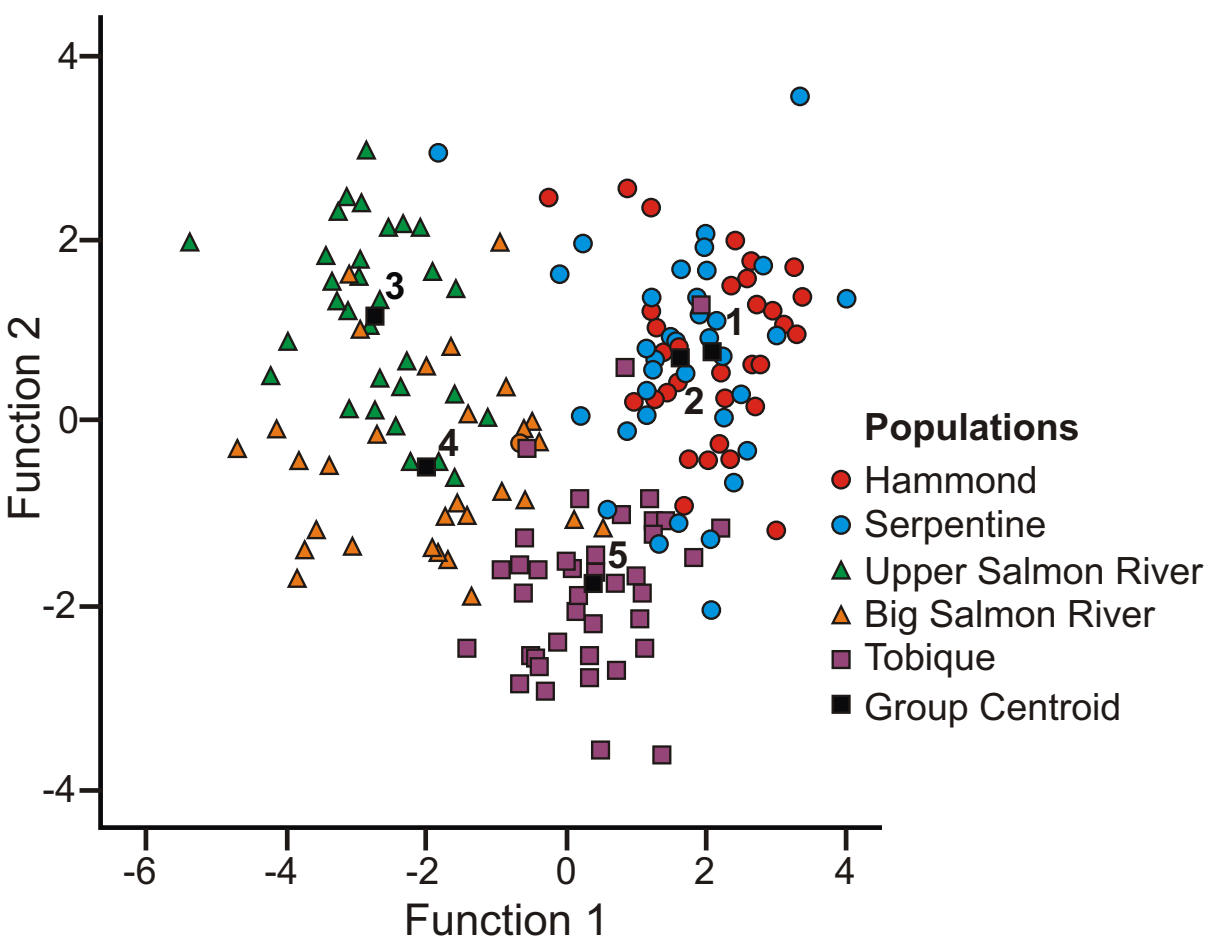

Fig. (4). Canonical variates ordination of five Atlantic salmon populations (centroids: 1.HAM, 2.SER, 3.USR, 4.BSR, 5.TOB) from discriminant analysis of aligned $\mathrm{x}$ and $\mathrm{y}$ coordinates. Increasing $\mathrm{X}$ axis (first canonical variate $66.6 \%$ ) represents decreasing body depth, shortening and narrowing of pectoral fins. Increasing Y axis (second canonical variate 48.4\%) represents increasing length of posterior end of fish, shortening and narrowing of pectoral fins, increase in body depth, and lowering of snout. Significant differences (t-test, Bonferroni $\alpha=0.0083$ ) were found between all pairs of salmon populations along canonical axis one except between HAM and SER and between USR and BSR. Significant differences between all pairwise comparisons were found along canonical axis two except between HAM and SER, between HAM and USR, and between SER and USR. 
Table 3a. Pairwise $F_{\text {ST }}$ Values (Below Diagonal) and $P$ Values ${ }^{1}$ (Above Diagonal) for All 195 Non-outlier SNPs Polymorphic in Five ${ }^{2}$ Atlantic Salmon Populations

\begin{tabular}{|c|c|c|c|c|c|}
\hline POP & BSR & HAM & SER & TOB & USR \\
\hline \hline BSR & & $0.005^{*}$ & $0.005^{*}$ & $0.005^{*}$ & $0.005^{*}$ \\
\hline HAM & 0.0542 & & 0.03260 & 0.0132 & $0.005^{*}$ \\
\hline SER & 0.0388 & 0.0608 & & $0.005^{*}$ \\
\hline TOB & 0.0404 & 0.0310 & 0.0276 & $0.005^{*}$ \\
\hline USR & 0.0453 & 0.0605 & 0.0734 & 0.0685 & \\
\hline
\end{tabular}

${ }^{1} P$ values obtained with FSTAT after 21,000 permutations. Exact $P$ values are shown.

${ }^{2}$ Pairwise $F_{\mathrm{ST}}$ values for all seven populations are presented in Supplementary Appendix D: Table 10S.

*Indicative adjusted nominal level for multiple comparisons with alpha $=0.05$

Table 3b. Pairwise $F_{\text {ST }}$ Values (Below Diagonal) and $P$ Values ${ }^{1}$ (Above Diagonal) for 12 Outlier SNPs in Five Atlantic Salmon Populations

\begin{tabular}{|c|c|c|c|c|c|}
\hline Population & BSR & HAM & SER & TOB & USR \\
\hline \hline BSR & & $0.00010^{*}$ & $0.00010^{*}$ & $0.00010^{*}$ & $0.00010^{*}$ \\
\hline HAM & 0.1578 & & $0.00010^{*}$ & $0.00010^{*}$ & $0.00010^{*}$ \\
\hline SER & 0.1921 & 0.1061 & & 0.00150 & $0.00010^{*}$ \\
\hline TOB & 0.1835 & 0.0846 & 0.0383 & & $0.00010^{*}$ \\
\hline USR & 0.1859 & 0.3264 & 0.3968 & 0.3839 & \\
\hline
\end{tabular}

$P$ values obtained with FSTAT after 21,000 permutations. Exact $P$ values are shown.

${ }^{2}$ Pairwise $F_{\text {ST }}$ values for all seven populations are presented in Supplementary Appendix D: Table 10S

$*$ Indicative adjusted nominal level for multiple comparisons with alpha $=0.05$

tion comparisons except for HAM and SER, HAM and USR, and SER and USR. We also carried out these aligned landmark analyses on seven populations with CHA and STC included with broadly similar results that confirmed that the CHA was the most distinctive in shape (Supplementary Appendix A: Tables 2S, 5S, 6S, 7S; Figs. (2S), (5S), (6S)). Discriminant analysis using partial warps gave very similar results to the aligned co-ordinate for both the five and seven populations datasets (Supplementary Appendix B: Tables 3S, 4S, 8S, 9S; Figs. (3S), (4S)). Geometric morphometric deformation grids depicting shape differences from the extremes of the first two functions of the canonical variates ordination of seven wild Atlantic salmon populations (Supplementary Appendix B: Fig. 7S).

\section{Molecular Population Differentiation}

A total of 207 SNP loci were heterozygous in the five focal populations. Only one non-outlier was significantly out of Hardy-Weinberg equilibrium and it was removed from subsequent analysis. We found statistically significant genetic differentiation for 9/10 (90\%) pair-wise comparisons of the five Atlantic salmon populations (Table 3; mean $F_{\mathrm{ST}}=$ 0.068 for all loci). USR had the highest three values $\left(F_{\mathrm{ST}}>\right.$ $0.095)$ for all the pair-wise comparisons that were made between all populations. Both $\mathrm{iBoF}$ populations (USR and BSR) were significantly differentiated from all three oBoF populations. Only SER and TOB were not significantly differentiated genetically from each other (Table 3 ).

\section{$F_{\text {ST }}$ Outlier Loci under Selection}

In the five-population analysis with Bayescan only the SNP in Contig 17368_0088 had "Strong" support using Jeffrey's scale of evidence $\left(\mathrm{N}=207\right.$ loci, $\mathrm{P}=0.92839, \log _{10}(\mathrm{PO})$ $=1.1127, \alpha=1.2252, F_{\mathrm{ST}}=0.22565$; Supplementary Appen$\operatorname{dix}$ F: Fig. 9S) and had a false discovery rate $(\mathrm{FDR})=0.07$. This contig codes for Triosephosphate isomerase 1b (Table 4).

The hierarchical island model also identified Contig 17368 0088 as well as five SNPs out of the 207 polymorphic SNPs as highly significant $F_{\mathrm{ST}}$-outlier levels of divergence and six additional SNPs that exhibited suggestive levels of divergence from that expected for neutral loci with the same level of heterozygosity (Table 4). Eight (3.9\%) SNP loci exhibited significant deviations from neutral expectations for $F_{\mathrm{ST}}$ and for $\mathrm{F}_{\mathrm{CT}}$ in the hierarchical island model and an additional four (1.9\%) SNP loci exhibited significant deviations from neutral expectations for $\mathrm{F}_{\mathrm{ST}}$ but not for $\mathrm{F}_{\mathrm{CT}}$ (Table 4, Supplementary Appendix F: Fig. 8S).

Table 5 shows that four of the significant and four of the suggestive outlier loci $(66 \%)$ were found to be on the same chromosome arms as previously discovered QTL for adaptive traits in parr such as, condition factor, parr mark contrast index, shape, and weight, found in backcrosses between 
Table 4. Six Outlier $(\mathbf{P}<\mathbf{0 . 0 1})$ and Six Suggestive Outlier $(\mathbf{0 . 0 1}<\mathbf{P}<\mathbf{0 . 0 5})$ SNPs Detected Using the Hierarchical Island Model Module of Arlequin 3.5 [55] from a Total of Mapped 207 SNPs, Polymorphic in the Five ${ }^{1}$ focal Atlantic Salmon Populations: BSR HAM, SER, TOB, and USR. Bayescan 2.0 Showed “Strong” Support for Contig 17368_0088 Using Jeffrey's Scale of Evidence (Supplementary Appendix F: Fig. 9S)

\begin{tabular}{|c|c|c|c|c|c|c|c|c|c|}
\hline Contig $^{2}$ & $\begin{array}{l}\text { SNP } \\
\text { Locus }^{3}\end{array}$ & Chr & Pos F & Pos M & $\mathbf{F}_{\mathrm{ST}}^{4}$ & $\mathbf{F}_{\mathbf{C T}}{ }^{5}$ & Homology/Gene & Species $^{6}$ & Conf. \\
\hline 14711_157 & 0075 & ssa3 & 12.9 & 51.2 & $0.33 * *$ & $0.24 * *$ & Galactosyltransferase & $\begin{array}{l}\text { T. nigroviri- } \\
\text { dis }\end{array}$ & $\begin{array}{c}1.00 \mathrm{E}+10 \\
7\end{array}$ \\
\hline 15686_55 & $0131 b$ & ssa13 $^{\#}$ & 48.8 & 1.6 & $0.25^{*}$ & $0.23 *$ & zgc: 63770, mRNA & D. rerio & $1.00 \mathrm{E}-27$ \\
\hline $15806 \_943$ & $0138 b$ & $\mathrm{ssa}^{\#}$ & 96.9 & 58.1 & $0.22 *$ & & heparin-binding neurite-promot factor & D. rerio & $3.00 \mathrm{E}-53$ \\
\hline 16129_0239 & 0156 & $\operatorname{ssa12} 2^{\#}$ & 110.5 & 6.5 & $0.39^{* * *}$ & $0.30^{* *}$ & trypsin inhibitor & $\begin{array}{l}\text { T. nigroviri- } \\
\quad \text { dis }\end{array}$ & $1.00 \mathrm{E}-100$ \\
\hline 16221_0769 & 0163 & $\operatorname{ssa} 22^{\#}$ & 42.5 & 1.0 & $0.19^{*}$ & & $\begin{array}{l}\text { 26S proteasome non-ATPase regl sub- } \\
\text { unit } 6\end{array}$ & S. salar & $0.00 \mathrm{E}+00$ \\
\hline 16260_0757 & 0168 & ssa20 & 39.7 & 0.5 & $0.30^{* *}$ & $0.17 * *$ & Beta-crystallin Bp & $\begin{array}{l}\text { T. nigroviri- } \\
\quad \text { dis }\end{array}$ & $2 \mathrm{E}-93$ \\
\hline 16466_1044 & 0181 & ssa05 & 33.9 & 42.5 & $0.37 * *$ & $0.25^{* *}$ & peptidase D & D. rerio & $6.00 \mathrm{E}-60$ \\
\hline $16710 \_407^{7}$ & 0199 & $\begin{array}{c}\text { ssa26/ } \\
28\end{array}$ & 9.2 & 2.7 & $0.25^{*}$ & $0.20^{*}$ & Anti-apoptotic protein NR13 & S. salar & $0.00 \mathrm{E}+00$ \\
\hline 16811_334 & 0208a & ssa09 & 71.4 & 4.9 & $0.19^{*}$ & & $\begin{array}{l}\text { Eukaryotic translation initiation factor 3- } \\
\qquad 1\end{array}$ & S. salar & $0.00 \mathrm{E}+00$ \\
\hline 16811_56 & $0208 b$ & $\mathrm{ssa}^{\#}$ & 71.4 & 4.9 & $0.19^{*}$ & & $\begin{array}{l}\text { Eukaryotic translation initiation factor 3- } \\
1\end{array}$ & S. salar & $0.00 \mathrm{E}+00$ \\
\hline 16958_0078 & 0227 & ssa14 & 60.5 & 1.7 & $0.26^{* *}$ & $0.16^{* *}$ & proteasome subunit beta 12 & D. rerio & $1.00 \mathrm{E}-113$ \\
\hline $173688_{7} 0088$ & 0252 & $\operatorname{ssa} 05^{\#}$ & 66.9 & 43.2 & $0.32 * *$ & $0.24 * *$ & triosephosphate isomerase $1 \mathrm{~b}$ & D. rerio & $1.00 \mathrm{E}-118$ \\
\hline
\end{tabular}

Note. ${ }^{*} \mathrm{P}<0.05,{ }^{*} \mathrm{P}<0.01$ (in bold), ${ }^{* * *} \mathrm{P}<0.001$ (in bold), blanks indicate non-significant; Chr: Chromosome and SNP position on female (F) and male (M) on the Canadian subspecies of Atlantic salmon map [83]. \# : SNP was not on Canadian map therefore chromosome and map position was inferred from the European map [74].

${ }^{1}$ EST-Loci Exhibiting $F_{\mathrm{ST}}$-Outlier Levels of Divergence for these five focal populations plus CHA are presented in Figure (10S).

${ }^{2}$ Name of Contiguous aligned DNA sequences from EST library (contig\#_SNP position in basepairs within contig).

${ }^{3}$ SNP name (official SNP alternative ID): the prefix Ssa precedes and the suffix ECIG follows the number given in the column so that 0014 becomes Ssa0014ECIG with those from the same locus (or Contig) indicated as a and $b$.

${ }^{4} \mathrm{~F}_{\mathrm{CT}}$ Arlequin test for significant genetic structure between inner and outer Bay of Fundy metapopulations at this locus (Fig. 8Sa).

${ }^{5} F_{\text {ST }}$ Arlequin test for significant genetic structure among populations once the metapopulation effect is removed (Fig. 8Sb).

${ }^{6}$ D. rerio $=$ Danio rerio, $T$. nigroviridis $=$ Tetraodon nigroviridis, S. salar $=$ Salmo salar.

${ }^{7}$ MSV-3 indicating that two duplicate loci exist but only the variable locus has been mapped [74] and is the "SNP" genotyped in this paper.

North American and European Atlantic salmon. The outlier locus found by both programs, triosephosphate isomerase $1 \mathrm{~b}$, is on a chromosome Ssa05 that is also known to contain a QTL for body shape.

Outlier analysis of six populations (BSR, HAM, SER, TOB, USR and CHA) identified an overlapping subset of 5 highly significant outlier loci using the hierarchical island model (Supplementary Appendix F: Fig. 10S) and also identified only SNP in Contig 17368_0088 using Bayescan (Supplementary Appendix F: Fig. 11 $\bar{S}$ ).

\section{Allele Frequencies at FST Outlier loci}

Only one of the $\mathrm{F}_{\mathrm{ST}}$-outlier loci (trypsin inhibitor) had allele frequencies that were perfectly correlated with $\mathrm{iBoF}$ and $\mathrm{oBoF}$ metapopulation structure (Table 6) but many other patterns were observed that should be tested in future studies. Within the oBoF, SER was fixed for the most frequent (major) allele at three high- $\mathrm{F}_{\mathrm{ST}}$ loci. TOB was almost fixed for the same three loci and was fixed for the major allele at a further three loci (Table 6). SER and TOB had different allele frequencies at two outlier loci that coded for $26 \mathrm{~S}$ proteasome non-ATPase regl subunit 6 and for zgc 63770. HAM was fixed at three loci but had much higher minor allele fre- 
quencies than the other populations at loci coding for heparin-binding neurite promotor factor and for Beta-crystallin Bp (Table 6). Within the iBoF, USR and BSR were fixed for one locus. BSR had especially high minor allele frequencies at loci coding for Anti-apoptotic protein NR13 and for Eukaryote translation initiation factor 3-1, whereas USR had particularly high minor allele frequencies at galactosyltransferase and at Aminopeptidase D (Tables 4, 6).

\section{Comparison of Molecular and Morphological divergence}

The average $F_{\mathrm{ST}}$ value was 0.05 over all 195 polymorphic non-outlier (="neutral") SNP markers but increased by more than three fold, to an average $F_{\mathrm{ST}}$ value of 0.231 , for the 12 SNP markers that were highly significant or suggestive outlier loci (Fig. 5). The higher amount of differentiation of outlier loci was also observed for the morphological characters (except landmark X1). Comparison of phenotypic $\left(P_{\mathrm{ST}}\right)$ and neutral genetic marker $\left(F_{\mathrm{ST}}\right)$ differentiation showed that overall differentiation in shape $\left(P_{\mathrm{ST}}\right)$ based on Procrustes distance for all landmarks was significantly larger than the overall differentiation in neutral genetic markers $\left(F_{\mathrm{ST}}\right)$ (Fig. 5). Landmarks Y3 representing variation in body height at the dorsal fin and $\mathrm{X} 1$ representing elongation/truncation of the tip of the snout showed exceptionally large $P_{\mathrm{ST}}$. The overall differentiation in body weight and centroid size $\left(P_{\mathrm{ST}}\right)$

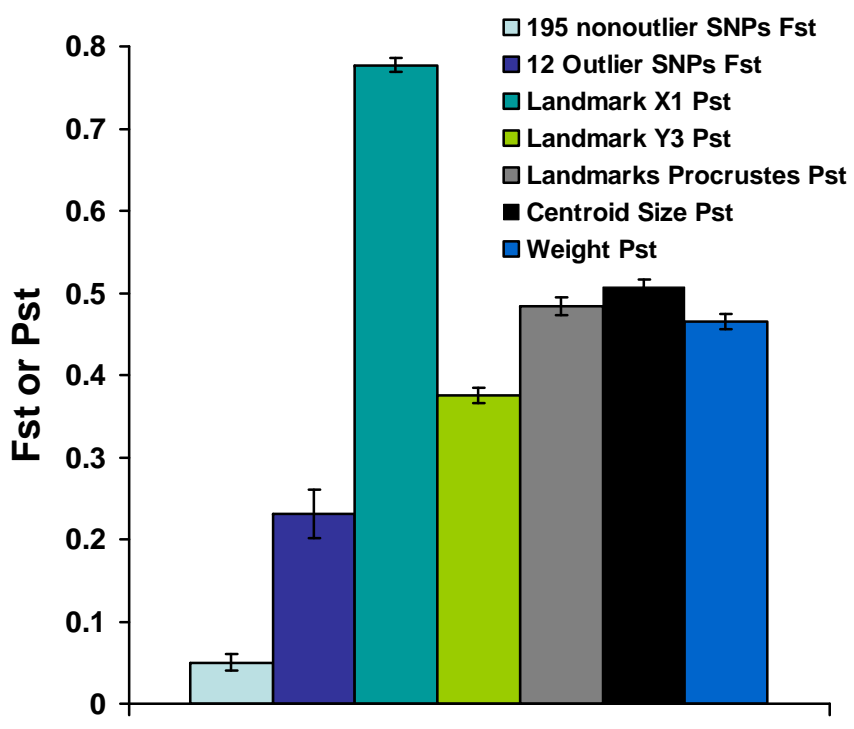

Measure of population structure

Fig. (5). Comparison of neutral and potentially adaptive variation among five populations. Average $F_{\mathrm{ST}}$ values and $95 \%$ confidence limits for all 195 nearly neutral polymorphic SNPs and for the twelve "outlier" SNP markers (Table 4). $P_{\mathrm{ST}}$ values (with $95 \%$ confidence limits from bootstrapping the data) for the two aligned landmarks $1 \mathrm{X}$ and $3 \mathrm{Y}$ that have the greatest size-free shape differences, Procrustes distance calculated using all landmarks (Table 2), for centro id size and for bodyweight.

Table 5. Summary of Four Outlier Loci ${ }^{1}$ (Bold Font) and Four Suggestive Loci, See Table 4) that Map to Chromosomes that Contain Quantitative Trait loci (QTLs) in Double-backcrosses between North American and European Atlantic salmon [32]

\begin{tabular}{|c|c|c|c|}
\hline Chr $^{2}$ & LG $^{3}$ & Contig & QTL $^{4}$ \\
\hline \hline ssa03 & 11 & $14711 \_157$ & Shape \\
\hline ssa05 & 12 & $16466 \_10441$ & Shape \\
\hline ssa05 & 12 & $17368 \_00881$ & Shape \\
\hline ssa7 & 24 & $15806 \_943$ & Shape, W1, W2, W3, CI1, CI2, CI3, PMC \\
\hline ssa09 & 10 & $16811 \_334$ & Shape \\
\hline ssa13 & 5 & $15686 \_55$ & Shape \\
\hline ssa14 & 3 & $16958 \_0078$ & Shape, W1, CI1 \\
\hline ssa26/28 & 21 & $16710 \_407$ & W3 \\
\hline
\end{tabular}

The SNP in Contig 16466_1044 and the SNP in Contig 17368_0088 were in complete linkage in male salmonid F1 hybrids parents used by Boulding et al. [32] but are showing some segregation in these wild populations (Table 4).

${ }^{2} \mathrm{Chr}=$ chromosome. SNP was not on Canadian map therefore chromosome and map position was inferred from the European map [74].

${ }^{3} \mathrm{LG}=$ linkage group containing SNP on male trans-Atlantic salmon map [32; unpubl. data for family A; Moen et al.[42].

${ }^{4}$ From Boulding et al. [32]: PMC = Parr mark Contrast Index, $\mathrm{W}=$ wet weight, $\mathrm{CI}=$ cuberoot of wet weight divided by total length (the suffixes refer to the measurement times: 1= 30 August to 4 September 2006, 2 = 10-18 November 2006 and 3=24-28 May 2007. 
was over six times higher than the average $F_{\mathrm{ST}}$ value for the non-outlier SNP loci.

There were two significant Mantel test results for the comparison of all seven salmon populations (Table 7). There was a positive correlation between the matrix of pairwise $F_{\mathrm{ST}}$ values for the 195 non-outlier loci (Supplementary Appendix D: Table 10S) and the matrix of the absolute value of the pairwise differences in body weight (Table 1) at transfer from the accelerated rearing facility (Table 7). There also was a positive correlation between the matrix of the absolute value of the pairwise differences in parr mark number and the matrix of the absolute value of the pairwise differences in parr mark contrast (Table 7, Supplementary Appendix D: Tables 12S, 13S).

\section{DISCUSSION}

\section{Signatures of Natural Selection}

We observed a phylogenetic signal between the $\mathrm{iBoF}$ and oBoF metapopulations in two ecophenotypic traits, growth

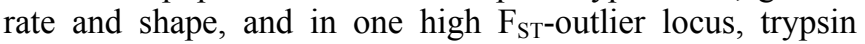
inhibitor. Molecular differentiation between the $\mathrm{BBoF}$ and oBoF metapopulations has been previously detected using AMOVA on SNP genotypes for eight populations [29] and by a distinctive mitochondrial DNA (mtDNA) haplotype found uniquely in the $\mathrm{iBoF}$ [30]. In our study, the $\mathrm{iBoF}$ populations (BSR and USR) had the longest jaw lengths whereas the oBoF populations (HAM, SER and TOB) had the shortest jaws suggesting that parr from the latter rivers feed on prey items that require a smaller gape. The phylogenetic signal affected two other morphological traits: $\mathrm{iBoF}$ parr populations grew more slowly and had deeper bodies with longer and wider pectoral fins than the oBoF popula- tions. Another outlier locus that codes for the regulatory glycolysis enzyme important in metabolism - Triosephosphate isomerase, had very low minor allele frequencies only in SER and TOB, was identified by both outlier programs, and has previously been identified as an outlier in another salmonid species [68].

More remarkably, we detected evidence for diversifying selection on SNPs that can not be explained by a phylogenetic signal and may represent adaptation to different stream velocities. In line with their close geographical proximity SER and TOB were not differentiated either at the neutral polymorphic SNP loci or at microsatellite loci [31]; however, they had different allele frequencies at two suggestive outlier SNP loci (26S proteasome non-ATPase regl subunit 6 and for zgc 63770) and also showed significant differences in body depth. In agreement with the life history effect on morphology suggested by Nicieza [69], the more slender SER is known to be the first population to migrate to the ocean and therefore would spend less time maintaining feeding territories than the populations like deeper-bodied TOB that migrates later (T. Goff pers. comm.). Different, and yet undocumented, environmental conditions in these two rivers that select for differences in migration times may also select for differences - in yet unknown traits - encoded by the regions of the genome near the two outlier loci. The chromosome locations under diversifying selection may vary among different geographical landscapes. Genotyping 26 Atlantic salmon populations from 7 regions of North America with a $6 \mathrm{~K}$ SNP chip resulted in 68 outlier loci [70] that did not overlap with the 12 outlier loci found here even though most of our 320 SNPs were present on the chip (S. Pedersen, unpubl. data).

In the common hatchery environment, HAM and SER

Table 6. $\quad F_{\text {ST }}$ Values from FSTAT V2.9.3 2 for Six Outlier (Bold Font) and Six Suggestive SNP Loci and their Minor Allele Frequencies from the Analysis of Five Atlantic Salmon Populations

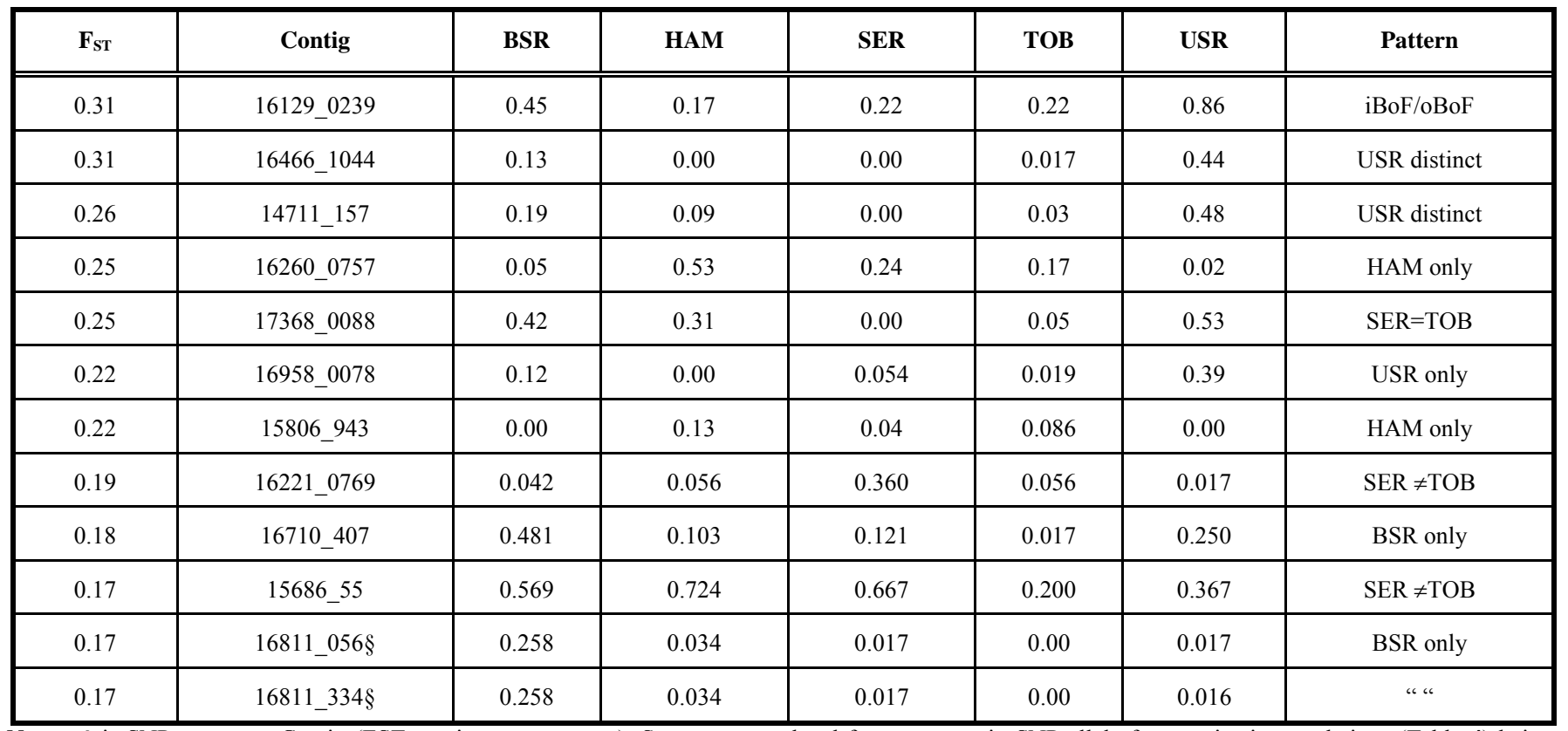

Notes: $\S$ is SNPs on same Contig (EST contiguous sequence); Structure postulated from patterns in SNP allele frequencies in populations (Table 4) being compared between various combinations of populations. 
Table 7. Mantel Tests Between Pairs of Untransformed Distance Matrices Among Seven Atlantic salmon populations: BSR, CHA, HAM, SER, TOB, STC and USR using MANTEL for Windows Version 1.19 [66]. One-tailed Probability that Z is Larger than $Z$ from Permutated Matrices with 100,000 Randomizations. Matrix Correlation Below Diagonal and One-tailed Probability Above Diagonal. $\mathrm{N}=21$

\begin{tabular}{|c|c|c|c|c|c|}
\hline Matrices & Body weight $^{1}$ & Body shape $^{2}$ & Number parr marks ${ }^{3}$ & Parr mark contrast $^{3}$ & $F_{\text {ST }} 195$ non-outlier loci ${ }^{4}$ \\
\hline Body weight & & 0.282 & 0.372 & 0.743 & $0.0245^{*, 5}$ \\
\hline Body shape & 0.0643 & & 0.640 & 0.907 & 0.350 \\
\hline N Parr marks & 0.0412 & -0.0835 & & $0.0108 *$ & 0.226 \\
\hline Parr mark contrast & -0.222 & -0.325 & 0.638 & & 0.738 \\
\hline$F_{\mathrm{ST}} 195$ non-outlier loci & 0.896 & -0.0180 & 0.415 & -0.220 & \\
\hline
\end{tabular}

Significant at $\alpha=0.05$.

$\mathbf{1}$ absolute value of the mean difference at transfer from Table $\mathbf{1 .}$

${ }^{2}$ pairwise Procrustes distance (Table 4, Supplementary Appendix D: Table 11S).

${ }^{3}$ Fig. (3); Supplementary Appendix D: Tables 12S, 13S

${ }^{4}$ Supplementary Appendix D: Table 10S.

${ }^{5}$ Correlation increases $\mathrm{r}=0.909, \mathrm{P}=0.0117$ when all 207 SNP loci are used.

had the most streamlined bodies with the smallest pectoral fins, whereas the USR and BSR populations had the deepest bodies and largest pectoral fins. Solem et al. [71] found shallow rivers with low gradients contained parr with narrower bodies and shorter pectoral fins than rivers with high gradients. Streams with steeper gradients, such as BSR, have increased water velocity, increased depth, and the substrate changing from mud to gravel [reviewed by 72]. Although HAM and SER were similar in body shape, parr mark number and parr mark contrast they had significantly different allele frequencies at neutral SNP loci, further supporting the convergent local adaptation hypothesis.

The same traits measured here: growth rate; body shape and the number and contrast of the parr marks were significantly associated with particular SNP alleles [32], and therefore, are likely to partially represent local genetic adaptation by juvenile salmonid populations [12]. In support of their adaptive function, 7 of the 12 outlier SNP loci we identified in this study were found to be on the same chromosome arms as QTL for shape, weight, condition, and parr mark contrast [32]. Other outlier loci were on the same chromosome arm as QTL for precocious maturity of male parr or early smolting [73]. However, the hybrid parents used in these studies $[32,73]$ were males which meant that a QTL was associated with all the SNP markers on that particular chromosome arm. Male salmonids experience almost no recombination except at the telomeres [74]. Previous studies looking for associations between particular $F_{\mathrm{ST}^{-}}$-outlier loci and QTL using non-model organisms experienced a similar problem. The use of a few hundred DNA markers and one or two generations of recombination [e.g. 57] does not allow fine scale linkage mapping of the QTL to determine whether the $\mathrm{F}_{\mathrm{ST}^{-}}$ outlier marker loci are the actual QTL. However, mapping resolution of QTL will improve as DNA marker density increases [75].

\section{Parr Mark Pigmentation}

Parr mark pigmentation patterns affect the ability of juvenile salmon to camouflage against the substrate so are likely to be under selection. The significant differences in the number of parr marks and in the contrast between the skin and the parr marks among Atlantic salmon populations reared together at Mactaquac hatchery, suggests a genetic component. Significant genetic differences in parr mark shape and number between native and introduced brown trout (Salmo trutta) occur in the Rhône drainage in France [76]. BSR, USR, and TOB had a relatively higher number of parr marks with high contrast suggesting adaptation to high stream gradient environments with gravel substrates [77]. BSR was confirmed to have a steep gradient but direct estimates for the other two rivers were not available. Conversely, HAM and SER had a relatively lower number of parr marks with low contrast suggesting adaptation to low gradient environments with a more homogeneous brown silt background [77]. A Mantel test showed that an increased number of parr marks was positively correlated with increased contrast; this could be a result of correlated selective pressures since the two traits seem to be controlled by sets of loci on different chromosomes [32].

Salmonids show some plasticity in pigmentation traits in response to environmental factors such as water clarity, diet and bottom structure [78] but the ability of a particular parr population to acclimate adaptively is limited. Atlantic salmon parr held in a channel with a brown background for several weeks develop parr marks with higher contrast than their relatives held in a channel with a tan background [79]. Further, when subsequently placed in either a brown or tan experimental channel, the parr from the brown channel with the high contrast parr marks was shown to always experience a higher rate of predation from hooded mergansers (Lophodytes cucullatus) than the parr from the tan channel with fainter parr marks [79]. That this particular population could not develop pigmentation that effectively camouflaged it against a brown background supports the hypothesis that differences in parr mark numbers and contrasts that we observed are the result of diversifying natural selection for particular stream bottom conditions. 


\section{Limitations of the Study}

The populations used in our study were captively-reared for future breeding and for wild release rather than specifically for our experiment. The eggs and early parr stages were reared in a common environment at the accelerated rearing facility. Two weeks before sampling the fish were transferred to the main hatchery and held at three different temperatures. Fortunately, the average weight of each population was measured just before transfer to the main hatchery which revealed that $\mathrm{iBoF}$ populations were already growing more slowly than the oBoF populations. Furthermore, the mean weight at sampling was not correlated with small temperature differences that the populations experienced during their final two-weeks of life, suggesting a minimal effect. Instead the Mantel test showed that mean weight at transfer was correlated with pairwise Fst values of the non-outlier loci, supporting our hypothesis of genetic differences in parr growth rates among these populations. However the fish were not photographed until two weeks after transfer, therefore a possible weakness of our study is that some of the shape and parr mark pigmentation differences detected in this paper could represent phenotypic plasticity in response to differences in rearing environment during these last two weeks. Two strengths of our study are that: 1) the phenotypic differences among the populations were detected in the environment that the captive breeding is actually taking place in and 2 ) the individuals were sampled from the actual crosses that were created for the captive breeding program.

$P_{\mathrm{ST}}$, the amount of population differentiation among the five Bay of Fundy salmon populations in adaptive phenotypic traits, was similar in magnitude to the mean $F_{\mathrm{ST}}$ for the outlier loci but was significantly greater than the mean $F_{\mathrm{ST}}$ for the non-outlier loci. Reviews by Merilä and Crnokrak [59] and by McKay and Latta [80] have suggested $\mathrm{Q}_{\mathrm{ST}}$ exceeding $F_{\mathrm{ST}}$ is a common pattern and supports the hypothesis of diversifying selection among populations. The caveat to this is that because we are using $P_{\mathrm{ST}}$ as a proxy for $\mathrm{Q}_{\mathrm{ST}}$ we do not know how much of the among-population variance is environmental variance caused by differences among tanks within the hatchery rather than heritable additive genetic variance. We obtained larger genetic distances among populations $\left(F_{\mathrm{ST}}\right)$ using only the six significant and six suggestive SNP markers at $F_{\mathrm{ST}}$-outlier loci rather than using all 195 non-outlier SNPs as was previously found by Freamo et al. [29]. This suggests that these outlier SNPs, or chromosomal regions in linkage disequilibrium with them, are under diversifying selection in different populations.

$F_{\text {ST }}$ estimates can be inflated by linkage disequilibrium arising from severe population bottlenecks involving a very low number of parents [see 46, 81]. The Colony analysis suggests that our estimates of $F_{\mathrm{ST}}$ were based on a moderately large sample of parents. Colony estimates that the five focal populations have average full-sib family sizes ranging from 1.1 to 3.6 suggesting that our sample of ( $\sim 30$ individuals) contains progeny from 8 to 27 different breeding pairs [29]. This is not surprising because the Live Gene Banking program is designed to minimize inbreeding by choosing mates so that kinship is minimized [3]. Further, $F_{\mathrm{ST}}$ estimates were not inflated by European ancestry since all fish with the diagnostic microsatellite alleles have been removed from the Live Gene Banking program [3].

\section{CONCLUSIONS}

Five endangered Atlantic salmon populations from the Bay of Fundy in New Brunswick, Canada, showed differences in parr growth rate, shape, and parr mark pigmentation in a common hatchery environment. With the exception of body weight, pairwise distances among these complex traits were not correlated with molecular genetic distance estimated from neutral SNP markers suggesting local genetic adaptation. Six EST-associated outlier SNP loci showed signatures of divergent natural selection. We propose that regions of the genome near these high $\mathrm{F}_{\mathrm{ST}}$-outlier loci may have diverged as a result of differential directional selection, perhaps during the parr stage when these populations would have experienced very diverse environmental conditions in their natal rivers.

\section{SUPPLEMENTARY MATERIAL}

Supplementary material is available on the publisher's web site along with the published article.

\section{CONFLICT OF INTEREST}

The authors confirm that this article content has no conflicts of interest.

\section{ACKNOWLEDGEMENTS}

Thanks to T. Goff for choosing our study populations and to D. MacDonald and their team of technicians for rearing the fish at Mactaquac Biodiversity Centre, Department of Fisheries and Oceans of Canada. Thanks also to A. Roseth and K. Sundsaasen of CIGENE for carrying out the SNP genotyping, M. Gjerstad of Photofisk for suggesting how to measure parr mark contrast, K. Parson for suggesting Procrustes distances, T.K. Hay for database programming, N. Chelbi for assistance with data collection, and I. Smith for improving the figures. The manuscript was much improved by comments from Bogart/Boulding/Fu lab group, W. Gibbs, T. Goff, T. Hay, D. Jackson, T. Moen, P. O'Reilly, A. Vasemägi, and anonymous reviewers. Funding was from Natural Sciences and Engineering Research Council of Canada grant STPGP 322406 - 2005 to EGB, I. Fleming and P. Schulte.

\section{SUPPLEMENTARY MATERIAL}

Supplementary material is available on the publisher's web site along with the published article.

\section{REFERENCES}

[1] Anonymous. Assessment and status report on the Atlantic Salmon Salmo salar. Canada Committee on the Status of Endangered Wildlife in Canada Ottawa, 2011, 136. Available at: http://wwwregistrelep sararegistrygcca/document/default_ecfm?documentID $=2258$

[2] Thorstad, E. B.; Whoriskey, F.; Rikardsen, A. H.; Aarestrup, K. Aquatic nomads: the life and migrations of the Atlantic salmon In 
Atlantic Salmon Ecology; Aas, Ø; Einum, S.; Klemetsen, A.; Skurdal, J., Eds.;Wiley-Blackwell: Singapore, 2011, pp. 1-32.

[3] O'Reilly, P.; Doyle, R. Live gene banking of endangered populations of Atlantic salmon; In: The Atlantic Salmon - Genetics, Conservation and Management; Verspoor, E.;Stradmeyer, L.Nielsen, J. L., Eds.; Blackwell Publishing Ltd: Oxford, 2007, pp. 425-469.

[4] Fraser, D. J.; Hutchings, J. A. In Parental divergence predicts the degree of outbreeding depression between farmed and wild Atlantic salmon; 61st Canadian Conference for Fisheries Research; 2008.

[5] Schindler, D. E.; Hilborn, R.; Chasco, B.; Boatright, C. P.; Quinn, T. P.; Rogers, L. A.; Webster, M. S. Population diversity and the portfolio effect in an exploited species. Nature, 2010, 465, 609612.

[6] Calderwood, W. L. The Life of the Salmon, $2^{\text {nd }}$ ed.; Edward Arnold: London, 1908, p. 160.

[7] Huntsman, A. G. "Races" and "homing" of salmon. Science, 1937, 85, 582-583.

[8] Ricker, W. J. Heredity and environmental factors affecting certain salmonid populations; In: The stock concept in Pacific salmon; R. C.; Larkin, P. A., Eds.; Oxford University Press: Simon, Oxford, 1972, pp. 44-57.

[9] Riddell, B. E.; Leggett, W. C. Evidence of an adaptive basis for geographic variation in body morphology and time of downstream migration of juvenile Atlantic salmon Salmo salar. Can. J. Fish. Aquat. Sci., 1981, 38, 308-320.

[10] Claytor, R. R.; MacCrimmon, H. R.; Gots, B. L. Continental and ecological variance components of European and North American Atlantic salmon (Salmo salar) phenotypes. Biol. J. Linn. Soc., 1991, 44, 203-229.

[11] Solem, Ø.; Berg, O. K. Morphological differences in parr of Atlantic salmon Salmo salar from three regions in Norway. J. Fish. Biol., 2011, 78, 1451-1469.

[12] Garcia de Leániz, C.; Fleming, I. A.; Einum, S.; Verspoor, E.; Jordan, W. C.; Consuegra, S.; Aubin-Horth, N.; Lajus, D.; Letcher, B. H.; Youngson, A. F.; Webb, J. H.; Voellestad, L. A.; Villanueva, B.; Ferguson, A.; Quinn, T. P. A critical review of adaptive genetic variation in Atlantic salmon: implications for conservation. Biol. Rev.; 2007, 82, 173-211.

[13] Fraser, D. J.; Weir, L. K.; Bernatchez, L.; Hansen, M. M.; Taylor, E. B. Extent and scale of local adaptation in salmonid fishes: review and meta-analysis. Heredity, 2011, 106, 404-420.

[14] Fraser, D. J.; Weir, L. K.; Darwish, T. L.; Eddington, J. D.; Hutchings, J. A. Divergent compensatory growth responses within species: linked to contrasting migrations in salmon? Oecologia, 2007, 153, 543-553.

[15] Darwish, T. L.; Hutchings, J. A. Genetic variability in reaction norms between farmed and wild backcrosses of Atlantic salmon (Salmo salar). Can. J. Fish. Aquat. Sci., 2009, 66, 83-90.

[16] Keeley, E. R.; Parkinson, E. A.; Taylor, E. B. The origins of ecotypic variation of rainbow trout: a test of environmental vs. genetically based differences in morphology. J. Evol. Biol., 2007, 20, 725-736.

[17] Hendry, A. P.; Wenburg, J. K.; Bentzen, P.; Volk, E. C.; Quinn, T. P. Rapid evolution of reproductive isolation in the wild: Evidence from introduced salmon. Science, 2000, 290, 516-518.

[18] Stearns, S. C.; Hendry, A. P. The salmonid contribution to key issues in evolution; In: Evolution Illuminated: Salmon and their Relatives; Hendry, A. P.;Stearns, S. C., Eds.; Oxford University Press: New York, 2004, pp. 3-19.

[19] Boulding, E. G.; Hay, T. Genetic and demographic parameters determining population persistence after a discrete change in the environment. Heredity, 2001, 86, 313-324.

[20] Pakkasmaa, S.; Piironen, J. Water velocity shapes juvenile salmonids. Evol. Ecol., 2000, 14, 721-730.

[21] Imre, I.; Mclaughlin, R. L.; Noakes, D. L. Phenotypic plasticity in brook charr: changes in caudal fin induced by water flow. J. Fish. Biol., 2002, 61, 1171-1181.

[22] Campbell, D. D.; Bernatchez, L. L. Generic scan using AFLP markers as a means to assess the role of directional selection in the divergence of sympatric whitefish ecotypes. Mol. Biol. Evol., 2004, $21,945-956$
[23] Rogers, S. M.; Bernatchez, L. Integrating QTL mapping and genome scans towards the characterization of candidate loci under parallel selection in the lake whitefish (Coregonus clupeaformis). Mol. Ecol., 2005, 14, 351-361.

[24] Vasemägi, A.; Nilsson, J.; Primmer, C. R. Expressed sequence taglinked microsatellites as a source of gene-associated polymorphisms for detecting signatures of divergent selection in Atlantic salmon (Salmo salarL.). Mol. Biol. Evol., 2005, 22, 1067-1076.

[25] Limborg, M. T.; Blankenship, S. M.; Young, S. F.; Utter, F. M.; Seeb, L. W.; Hansen, M. H.; Seeb, J. E. Signatures of natural selection among lineages and habitats in Oncorhynchus mykiss. Ecol. Evol., 2012, 2, 1-18.

[26] Storz, J. F. Using genome scans of DNA polymorphism to infer adaptive population divergence. Mol. Ecol. 2005, 14, 671-688.

[27] Helyar, S. J.; Hemmer-Hansen, J. J.; Bekkevold, D. D.; Taylor, M. I.; Ogden, R.; Limborg, M. T.; Cariani, A.; Maes, G. E.; Diopere, E.; Carvalho, G. R.; Nielsen, E. E. Application of SNPs for population genetics of nonmodel organisms: new opportunities and challenges. Mol. Ecol. Res., 2011, 11 Suppl 1, 123-136.

[28] Hayes, B.; Laerdahl, J. K.; Lien, S.; Moen, T.; Berg, P.; Hindar, K.; Davidson, W. S.; Koop, B. F.; Adzhubei, A.; Hoyheim, B. An extensive resource of single nucleotide polymorphism markers associated with Atlantic salmon (Salmo salar) expressed sequences. Aquaculture, 2007, 265, 82-90.

[29] Freamo, H.; O'Reilly, P.; Berg, P. R.; Lien, S.; Boulding, E. G. Outlier SNPs show more genetic structure between two Bay of Fundy metapopulations of Atlantic salmon than do neutral SNPs. Mol. Ecol. Res., 2011, 11, 254-267.

[30] Verspoor, E.; O'Sullivan, M.; Arnold, A. L.; Knox, D.; Amiro, P. G. Restricted matrilineal gene flow and regional differentiation among Atlantic salmon (Salmo salarL.) populations within the Bay of Fundy, eastern Canada. Heredity, 2002, 89, 465-472.

[31] Vandersteen-Tymchuk, W.; O'Reilly, P. B., J.; MacDonald, D.; Schulte, P. Conservation genomics of Atlantic salmon: variation in gene expression between and within regions of the Bay of Fundy. Mol. Ecol., 2010, 19, 1842-1859.

[32] Boulding, E. G.; Culling, M.; Glebe, B.; Berg, P. R.; Lien, S.; Moen, T. Conservation genomics of Atlantic salmon: SNPs associated with QTLs for adaptive traits in parr from four trans-Atlantic backcrosses. Heredity, 2008, 101, 381-391.

[33] Rohlf, F. J. tpsDig, digitize landmarks and outlines, 2002, version 1.37 Department of Ecology and Evolution, State University of New York at Stony Brook. Available at http://life.bio.sunysb.edu/morph/

[34] Parsons, K. J.; Robinson, B. W.; Hrbek, T. Getting into shape: an empirical comparison of traditional truss-based morphometric methods with a newer geometric method applied to New World cichlids. Environ. Biol. Fish., 2003, 67, 417-431.

[35] Rohlf, F. J. tpsRelw, relative warps analysis, 2010, version 1.31. Department of Ecology and Evolution, State University of New York at Stony Brook. Available at: http://life.bio.sunysb.edu/morph/

[36] Rohlf, F. J.; Slice, D. S. Extensions of the Procrustes method for the optimal superimposition of landmarks. Syst. Zool.; 1990, 39, 40-59.

[37] Rohlf, F. J. tpsRegr, shape regression, 2003, version 1.28. Department of Ecology and Evolution, State University of New York at Stony Brook. Available at: http://life.bio.sunysb.edu/morph/index. html

[38] Bookstein, F. L. Morphometric tools for landmark data: geometry and biology.; Cambridge University Press: Cambridge, 1991; $\mathrm{p}$ 456.

[39] Walker, J. A. Ecological morphology of lacustrine three-spine stickleback Gasterosteus aculeatus L (Gasterosteidae) body shape. Biol. J. Linn. Soc., 1997, 61, 3-50.

[40] Parsons, K. J.; Sheets, H. D.; Sku' lason, S.; Ferguson, M. M. Phenotypic plasticity, heterochrony and ontogenetic repatterning during juvenile development of divergentArctic charr (Salvelinus alpinus). J. Evol. Biol., 2011, 24, 1640-1652.

[41] de Leaniz, C. G.; Fleming, I. A.; Einum, S.; Verspoor, E.; Consuegra, S.; Jordan, W. C.; Aubin-Horth, N.; Lajus, D. L.; Villanueva, B.; Ferguson, A.; Youngson, A. F.; Quinn, T. P. Local Adaptation; 
In: The Atlantic Salmon - Genetics, Conservation and Management; Verspoor, E.; Stradmeyer, L.; Nielsen, J. L., Eds.; Blackwell: Oxford, 2007, pp. 195-235.

[42] Moen, T.; Hayes, B.; Baranski, M.; Berg, P. R.; Kjoeglum, S.; Koop, B. F.; Davidson, W. S.; Omholt, S. W.; Lien, S. A linkage map of the Atlantic salmon (Salmo salar) based on EST-derived SNP markers. BMC Genomics, 2008, 9, 223.

[43] Bourret, V.; Kent, M. P.; Primmer, C. R.; Vasemägi, A.; Karlsson, S.; Hindar, K.; McGinnity, P.; Verspoor, E.; Bernatchez, L.; Lien, S. SNP-array reveals genome-wide patterns of geographical and potential adaptive divergence across the natural range of Atlantic salmon (Salmo salar). Mol. Ecol., 2013, 22, 532-551.

[44] Weir, B. S.; Cockerham, C. C. Estimating F-statistics for the analysis of population structure. Genetics, 1984, 38, 1358-1370.

[45] Goudet, J. FSTAT 291 a program to estimate and test gene diversities and fixation indices. 2000, Available at: http://www. unilch/izea/softwares/fstathtml

[46] Allendorf, F. W.; Phelps, S. R. Loss of genetic variation in a hatchery stock of cutthroat trout. Trans. Am. Fish. Soc., 1980, 109, 537543.

[47] Foll, M.; Gaggiotti, O. A genome-scan method to identify selected loci appropriate for both dominant and codominant markers: a Bayesian perspective. Genetics, 2008, 180, 977-993.

[48] Beaumont, M. A.; Nichols, R. A. Evaluating loci for use in the genetic analysis of population structure. Proc. R. Soc. Lond. B Biol. Sci., 1996, 263, 1619-1626.

[49] Beaumont, M. A.; Balding, D. J. Identifying adaptive genetic divergence among populations from genome scans. Mol. Ecol., 2004, 13, 969-980.

[50] Foll, M. BayeScan v2.0 User Manual. (unpublished). Available at: http://cmpg.unibe.ch/software/bayescan/files/bayescan2.0 manual. pdf [Accessed February 1, 2013].

[51] Limborg, M. T.; Helyar, S. J.; de Bruyn, M.; Taylor, M. I.; Nielsen, E. E.; Ogden, R.; Carvalho, G. R.; FPT Consortium; Bekkevold, D. Environmental selection on transcriptome-derived SNPs in a high gene flow marine fish, the Atlantic herring (Clupea harengus). Mol. Ecol., 2012, 21, 3686-3703.

[52] Limborg, M. T.; Helyar, S. J.; de Bruyn, M.; Taylor, M. I.; Nielsen, E. E.; Ogden, R.; Carvalho, G. R.; FPT Consortium; Bekkevold, D. Corregendum: Mol. Ecol., 2013,22, 2355-2356.

[53] Narum, S. R.; Hess, J. E. Comparison of F(ST) outlier tests for SNP loci under selection. Mol. Ecol. Res., 2011, 11 Suppl 1, 184194.

[54] Slatkin, M.; Voelm, L. FST in a hierarchical island model. Genetics, 1991, 127, 627-629.

[55] Excoffier, L.; Hofer, T.; Foll, M. Detecting loci under selection in a hierarchically structured population. Heredity, 2009, 103, 285-298.

[56] Excoffier, L.; Lischer, H. E. Arlequin suite ver 3.5: a new series of programs to perform population genetics analyses under Linux and Windows. Mol. Ecol. Res., 2010, 10, 564-567.

[57] Rogers, S. M.; Bernatchez, L. The genetic architecture of ecological speciation and the association with signatures of selection in natural lake whitefish (Coregonussp. Salmonidae) species pairs. Mol. Biol. Evol., 2007, 24, 1423-1438.

[58] Mäkinen, H. S.; Cano, J. M.; Merilä, J. Identifying footprints of directional and balancing selection in marine and freshwater threespined stickleback (Gasterosteus aculeatus) populations. Mol. Ecol., 2008, 17, 3565-3582.

[59] Merilä, J.; Crnokrak, P. Comparison of genetic differentiation at marker loci and quantitative traits. J. Evol. Biol., 2001, 14, $892-$ 903.

[60] Leinonen, T.; O'Hara, R. B.; Cano, J. M.; Merilä, J. Comparative studies of quantitative trait and neutral marker divergence: a metaanalysis. J. Evol. Biol., 2008, 21, 1-17.

[61] Merilä, J. Quantitative trait and allozyme divergence in the Greenfinch (Carduelis chloris, Aves: Fringillidae). Biol. J. Linn. Soc., 1997, 61, 243-266.

[62] Storz, J. F. Contrasting patterns of divergence in quantitative traits and neutral DNA markers: analysis of clinal variation. Mol. Ecol., 2002, 11, 2537-2551.

[63] Leinonen, T.; Cano, J. M.; Mäkinen, H.; Merilä, J. Contrasting patterns of body shape and neutral genetic divergence in marine and lake populations of threespine sticklebacks. J. Evol. Biol., 2006, 19, 1803-1812.

[64] Falconer, D. S.; Mackay, T. In Introduction to quantitative genetics, $4^{\text {th }}$ ed., Harlow: UK, 1996, p 480.

[65] Quinton, C. D.; McMillan, I.; Glebe, B. D. Development of an Atlantic salmon (Salmo salar) genetic improvement program: Genetic parameters of harvest body weight and carcass quality traits estimated with animal models. Aquaculture, 2005, 247, 211-217.

[66] Cavalcanti, M. J. Program for Mantel test, 2008, version 1.19 Centro de Ciências Biológicas, Universidade Santa Úrsula. Available at: http://life.bio.sunysb.edu/morph/index.html2008).

[67] Sheets, H. D. IMP7, 2011, Dept. of Physics, Canisius College, Buffalo, NY 14208 USA. Available at http://www3.canisius.edu/ sheets/imp7.htm

[68] Renaut, S.; Nolte, A. W.; Rogers, S. M.; Derome, N.; Bernatchez, L. SNP signatures of selection on standing genetic variation and their association with adaptive phenotypes along gradients of ecological speciation in lake whitefish species pairs (Coregonus spp.). Mol. Ecol., 2011, 20, 545-559.

[69] Nicieza, A. G. Morphological variation between geographically disjunct populations of Atlantic salmon: The effects of ontogeny and habitat shift. Funct. Ecol., 1995, 9, 448-456.

[70] Bourret, V.; Dionne, M.; Kent, M. P.; Lien, S.; Bernatchez, L. Landscape genomics in Atlantic salmon (Salmo salar): searching for gene-environment interactions driving local adaptation. Evolution, 2013, DOI: 10.1111/evo.12139, July 30, 2013.

[71] Solem, Ø; Berg, O. K.; Kjøsnes, A. J. Inter- and intra-population morphological differences between wild and farmed Atlantic salmon juveniles. J. Fish. Biol., 2006, 69, 1466-1481.

[72] Amiro, P. G. Habitat measurement and population estimation of juvenile Atlantic salmon (Salmo salar). In: Gibson, R. J.; Cutting, R. E., Eds.; Production of Juvenile Atlantic Salmon, Salmo salar, in Natural Waters. Canadian Special Publication of Fisheries and Aquatic Sciences, NRC Press: Ottawa, 1993, vol. 118; pp. 81-97.

[73] Pedersen, S.; Berg, P. R.; Culling, M.; Danzmann, R. G.; Glebe, B. D.; Leadbeater, S.; Lien, S.; Moen, T.; Vandersteen, W.; Boulding, E. G. Quantitative trait loci for precocious parr maturation, early smoltification, and adult maturation in double-backcrossed transAtlantic salmon (Salmo salar). Aquaculture, 2013, 410-411, 164 171.

[74] Lien, S.; Gidskehaug, L.; Moen, T.; Hayes, B. J.; Berg, P. R.; Davidson, W. S.; Omholt, S. W.; Kent, M. P. A dense SNP-based linkage map for Atlantic salmon (Salmo salar) reveals extended chromosome homeologies and striking differences in sex-specific recombination patterns. BMC Genomics, 2011, 12, 615.

[75] Boulding, E. G. Role of phenotypically-informative SNP markers in conservation biology, editorial. I. J. Evol., 2012, 1, 1.

[76] Mezzera, M.; Largiader, C. R.; Scholl, A. Discrimination of native and introduced brown trout in the River Doubs (Rhone drainage) by number and shape of parr marks. J. Fish. Biol., 1997, 50, 672677.

[77] Donnelly, W. A.; Dill, L. M. Evidence for crypsis in coho salmon,Oncorhynchus kisutch(Walbaum), parr: Substrate colour preference and achromatic reflectance. J. Fish. Biol., 1984, 25, 183195.

[78] Bourke, P.; Magnan, P.; Rodriguez, M. A. Individual variations in habitat use and morphology in brook charr. J. Evol. Biol., 1997, 51, 783-794.

[79] Donnelly, W. A.; Whoriskey, F. G. J. Transplantation of Atlantic salmon (Salmo salar) and crypsis breakdown; In: Production of juvenile Atlantic salmon,Salmo salar, in natural waters; Gibson, $\mathrm{R}$. J.;Cutting, R. E., Eds.; Can. Spec. Publ. Fish. Aquat. Sci.: Ottawa, 1993; vol. 118, pp. 25-34.

[80] McKay, J. K.; Latta, R. G. Adaptive population divergence: markers, QTL and traits. TREE, 2002, 17, 285-291.

[81] Lemay, M. A.; Boulding, E. G. Microsatellite pedigree analysis reveals high variance in reproductive success and reduced genetic diversity in hatchery-spawned northern abalone. Aquaculture, 2009, 295, 22-29.

[82] Caissie, D.; El-Jabi, N.; Alexander, D. R. Instream Flow Data for Atlantic Canada; Canadian Data Report of Fisheries and Aquatic Sciences; NRC: Ottawa, 1994, p. 946. 
[83] Brenna-Hansen, S.; Li, J.; Kent, M. P.; Boulding, E. G.; Dominik, S.; Davidson, W. S.; Lien, S. Chromosomal differences between European and North American Atlantic salmon discovered by linkage mapping and supported by fluorescence in situ hybridization analysis. BMC Genomics, 2012, 13, 432.

[84] Douglas, M. E.; Douglas, M. R.; Lynch, J. M.; McElroy, D. M. Use of geometric morphometrics to differentiate Gila (Cyprinidae) within the Upper Colorado River Basin. Copeia, 2001, 2001, 389400 .

[85] Langerhans, R. B.; DeWitt, T. J. Shared and unique features of evolutionary diversification. Am. Nat., 2004, 164, 335-349.

[86] Wang, J. Colony, 2012, version 2.031. Senior Research Fellow, Institute of Zoology. Available at: https://www.zsl.org/science/research- projects/software/colony,1154,AR.html
[87] Wang, J. Computationally efficient sibship and parentage assignment from multilocus marker data. Genetics, 2012, 191, 183-194.

[88] Pritchard, J. K.; Stephens, M.; Donnelly, P. Inference of population structure using multilocus genotype data. Genetics, 2000, 155, 945959.

[89] Falush, D.; Stephens, M.; Pritchard, J. K. Inference of population structure using multilocus genotype data: linked loci and correlated allele frequencies. Genetics, 2003, 164, 1567-1587.

[90] Evanno, G.; Regnaut, S.; Goudet, J. Detecting the number of clusters of individuals using the software STRUCTURE: a simulation study. Mol. Ecol., 2005, 14, 2611-2620.

[91] Fischer, M. C.; Foll, M.; Excoffier, L.; Heckel, G. Enhanced AFLP genome scans detect local adaptation in high altitude populations of a small rodent (Microtus arvalis). Mol. Ecol., 2011, 20, 1450-1462.

Received: May 04, 2013

Revised: May 08, 2013

Accepted: May 08, 2013

(c) Culling et al.; Licensee Bentham Open.

This is an open access article licensed under the terms of the Creative Commons Attribution Non-Commercial License (http://creativecommons.org/licenses/ by-nc/3.0/) which permits unrestricted, non-commercial use, distribution and reproduction in any medium, provided the work is properly cited. 